\title{
Pengelompokkan Kelas Menggunakan Self Organizing Map Neural Network pada SMK N 1 Depok
}

\author{
Eko Harli ${ }^{\# 1}$, Ahmad Fauzi ${ }^{\# 2}$, Tria Hadi Kusmanto ${ }^{\# 3}$ \\ ${ }^{\text {\#} F a k u l t a s ~ T e k n i k, ~ U n i v e r s i t a s ~ I n d r a p r a s t a ~ P G R I ~ J a k a r t a ~}$ \\ Jln. Nangka No.58C, Tanjung Barat, Jakarta \\ lekoharli@gmail.com \\ 2ahmadfauzi.udzi@gmail.com \\ 3triahadikusmanto@yahoo.com
}

\begin{abstract}
Abstrak - Dalam mengembangkan kegiatan belajar di sekolah terutama di dalam kelas agar terciptanya suasana yang nyaman sehingga dapat pula memacu perkembangan siswa dalam belajar agar dapat meningkatkan kualiatas pendidikan di Indonesia perlu adanya suatu pengaturan siswa dalam sebuah kelas. Pada penelitian ini ANN digunakan untuk membangun sebuah model pengelompokkan siswa dalam sebuah kelas secara mudah berdasarkan nilai raport siswa menggunakan metode alogritma Self Organizing Map (SOM). Berdasarkan uraian yang telah peneliti paparkan, maka dalam penelitian ini peneliti akan membuat aplikasi Pengelompokkan Kelas Menggunakan Self Organizing Map Neural Network Pada SMK Negeri 1 Depok. Tujuan dari penelitian ini adalah untuk membangun model pengelompokan kelas secara mudah. Penelitian ini melakukan penentuan klasifikasi kelas berdasarkan nomor induk siswa, nilai mata pelajaran siswa, jenis kelamin dan nilai sikap siswa menggunakan algoritma Self Organizing Map. Data siswa dimasukan kedalam sistem kemudian dilakukan klasifikasi kelas berdasarkan nilai-nilai siswa yang baik dan kurang baik menggunakan SOM, selanjutnya pemerataan hasil klasifikasi agar setiap kelas mendapatkan hasil yang merata dari nilai siswa tersebut. Hasil yang diperoleh setelah dilakukan klasifikasi menggunakan SOM yaitu pengelompokan siswa yang merata dan dibagi kedalam dua kelas
\end{abstract}

Kata kunci - Cluster, Self-Organizing Map, Neural Network, Kelas, Kelompok Belajar

\section{Pendahuluan}

Pemerintah Indonesia terus berupaya untuk meningkatkan mutu dan kualitas pendidikan, salah satunya dengan diterbitkannya Kurikulum 2013 (K-13) oleh Kementerian Pendidikan dan Kebudayaan Republik Indonesia. Kedalaman muatan kurikulum pada setiap satuan pendidikan dituangkan dalam kompetensi yang terdiri atas standar kompetensi (SK) dan kompetensi dasar (KD) pada setiap tingkat dan/ atau semester, SK dan KD inilah yang menjadi arah dan landasan untuk mengembangkan materi pokok, kegiatan pembelajaran, dan indikator pencapaian kompetensi untuk penilaian [1].

Pengingkatan perkembangan kegiatan pembelajaran tidak lepas dari suasana sekolah terutama kelas yang menjadi lingkungan keseharian siswa. Suasana yang nyaman dan kekeluargaan tanpa ada perbedaan satu sama lain dapat meningkatkan perkembangan siswa dalam belajar. Karena hal tersebut, maka perlu suatu bentuk pengaturan siswa dalam sebuah kelas atau kelompok belajar.

Alasan pengelompokan peserta didik juga didasarkan atas realitas bahwa peserta didik secara terus-menerus bertumbuh dan berkembang. Pertumbuhan dan perkembangan peserta didik satu dengan yang lain berbeda. Agar perkembangan peserta didik yang cepat tidak mengganggu peserta didik yang lambat dan sebaliknya, maka dilakukanlah pengelompokan peserta didik [2].

Manajemen kelas yang baik dapat menciptakan kondisi pembelajaran yang menguntungkan, dan merupakan tindakan koreksi terhadap tingkah laku menyimpang yang dapat mengganggu kondisi optimal dari proses pembelajaran yang sedang berlangsung [3].

Pengelompokan atau grouping adalah pengelompokan peserta didik berdasarkan karakteristik-karakteristiknya [4]. Karakteristik demikian perlu digolongkan, agar mereka berada dalam kondisi yang sama. Adanya kondisi yang sama ini bisa memudahkan pemberian layanan yang sama. Oleh kerena itu, pengelompokan (grouping) ini lazim dengan istilah pengklasifikasian (clasification). Pengelompokan siswa diadakan dengan maksud agar pelaksanaan kegiatan proses belajar mengajar di sekolah bisa berjalan lancar, tertib, dan bisa tercapai tujuan-tujuan pendidikan yang telah diprogramkan [5].

Untuk tujuan pengelompokkan siswa maka dilakukan identifikasi siswa dengan cara segmentasi menggunakan analisis cluster. Ada bermaca-macam metode untuk melakukan analisis cluster, mulai dari metode yang sederhana hingga metode yang kompleks dengan menggunakan kecerdasan tiruan seperti jaringan syaraf tiruan (Artificial Neural Network)

Metode jaringan syaraf tiruan untuk melakukan clustering adalah metode jaringan syaraf yang menggunakan pola unsupervised learning, salah satunya yaitu Kohonen's Self-Organizing Maps.

Self-Organizing Maps (SOM) telah banyak diaplikasikan pada penelitian yang menghasilkan klasifikasi dari sejumlah data. Dessy dan Fajriya [6] dalam penelitiannya telah mengaplikasikan algoritma SOM untuk mengklasifikasikan kondisi indikator pembangunan berkelanjutan di Indonesia, 
hasilnya terdapat 5 cluster dengan karakteristik yang berbedabeda. Gregorius, Liliana, dan Steven [7] dalam penelitiannya telah mengaplikasikan SOM untuk memprediksi talenta pemain yang sesuai dengan cluster tertentu. Kartika Purwandari, Candra Dewi, Imam Cholissodin [8] menggunakan SOM untuk mengklasifikasikan citra daun. Yunus dan Rizal [9] menerapkan metode SOM untuk visualisasi data geospasial pada informasi sebaran data pemilih. Sedangkan Mishra dkk [10] menerapkan SOM untuk klasifikasi High Dimensional Data Set.

Penelitian ini menerapkan SOM untuk mengklasifikasikan siswa kedalam 2 cluster atau lebih secara merata berdasarkan nilai-nilai parameter yang menggambarkan siswa tersebut. Hasil dari klasifikasi tersebut akan berguna untuk guru dalam menentukan pengaturan dari sebuah kelas.

\section{TinjauAn Pustaka}

\section{A. Dasar Pengelompokkan Peserta Didik}

Dasar-dasar pengelompokkan peserta didik ada 5 macam yaitu [2]:

1) Friendship Grouping: Pengelompokkan peserta didik yang didasarkan atas kesukaan memilih teman.

2) Achievement Grouping: Pengelompokkan yang didasarkan atas prestasi peserta didik.

3) Aptitude Grouping: Pengelompokkan peserta didik yang didasarkan atas kemampuan dan batas mereka.

4) Attention dan Interest Gouping: Pengelompokan peserta didik yang didasarkan atas perhatian mereka atau minat mereka.

5) Intelegence Grouping: Pengelompokan yang didasarkan atas hasil tes kecerdasan atau intelegensi.

\section{B. Jenis Pengelompokkan Peserta Didik}

Kelompok-kelompok kecil pada masing-masing kelas demikian dapat dibentuk berdasarkan karakteristik individu. Ada beberapa macam kelompok kecil di dalam kelas ini, yaitu [3]:

1) Interest Grouping: Pengelompokan yang didasarkan atas minat peserta didik.

2) Special Need Grouping: Pengelompokan berdasarkan kebutuhan-kebutuhan khusus peserta didik.

3) Team Grouping: Pengelompokkan yang terbentuk karena dua atau lebih peserta didik ingin bekerja dan belajar bersama untuk memecahkan masalah-masalah khusus.

4) Tutorial Grouping: Pengelompokan di mana peserta didik bersama-sama dengan guru merencanakan kegiatankegiatan kelompoknya.

5) Research Grouping: Pengelompokan dimana dua atau lebih peserta didik menggarap suatu topik penelitian untuk dilaporkan di depan kelas.
6) Full-Class Group: Pengelompokan dimana peserta didik secara bersama-sama mempelajari dan mendapatkan pengalaman dibidang seni.

7) Combined Class Grouping: Pengelompokan di mana dua atau lebih kelas yang dikumpulkan dalam suatu ruangan untuk bersama-sama menyaksikan pemutaran film, slide, TV dan media audio visual lainnya.

\section{Artificial Neural Network}

Pemrosesan informasi yang didesain dengan menirukan cara kerja otak manusia dalam menyelesaikan suatu masalah merupakan salah satu sistem Artificial Neural Network (ANN) sebagai cabang dari ilmu kecerdasan buatan Artificial Intelligence (AI). Alexander dan Morton dalam Suyanto [11] mendefinisikan ANN sebagai prosesor tersebar paralel yang sangat besar yang memiliki kecendeungan untuk menyimpan pengetahuan yang bersifat pengalaman dan membuatnya untuk siap digunakan. Pengertian lain mendefinisikan ANN adalah sistem pemroses informasi yang memiliki karakteristik mirip dengan jaringan syaraf biologi [12].

ANN dibentuk sebagai generalisasi model matematika dari jaringan syaraf biologi dengan mengasumsikan pemrosesan informasi terjadi pada banyak elemen sederhana (neuron); sinyal dikirimkan diantara neuron-neron melalui penghubungpenghubung; penghubung antar neuron memiliki bobot yang akan memperkuat atau memperlemah sinyal; dan untuk menentukan output setiap neuron menggunakan fungsi aktivasi yang dikenakan pada jumlahan input yang diterima, besarnya output ini selanjutnya dibandingkan dengan suatu batas ambang. Dengan demikian ANN ditentukan oleh tiga hal, yaitu: pola hubungan antar neuron (disebut arsitektur jaringan); metode untuk menentukan bobot penghubung (disebut metode training/learning/algoritma); dan fungsi aktivasi.

\section{Self-Organizing Map (SOM)}

Self-Origanizing Map (SOM) adalah saah satu tool yang sangant baik dalam penanganan data yang sangat besar (datamining) [13].

SOM merupakan suatu metode jaringan syaraf tiruan yang diperkenalkan sekitar tahun 1980an oleh Professor Teuyo Kohonen. SOM merupakan salah satu bentuk topologi dari Unsupervised Artificial Neural Network (Unsupervised ANN) dimana dalam proses pelatihannya tidak memerlukan pengawasan (target output). SOM digunakan untuk mengelompokkan (clustering) data berdasarkan karakteristik / fitur-fitur data [14] [15] [16]. Arsitektur dari SOM dapat dilihat pada Gambar 1 yang diambil dari [7]:

Berikut adalah algoritma SOM [7], [17]:

1. Inisialisasi neuron input : $x_{1}, x_{2}, \ldots, x_{1}$.

2. Inisialisasi neuron output (lapisan output) sebanyak j $x 1: y_{11}, y_{12}, \ldots, y_{j 1}$

3. Mengisi bobot antar neuron input dan output $\mu_{i j l}$ dengan bilangan random 0 sampai 1 .

4. Mengulangi langkah 5 sampai dengan langkah 8 hingga tidak ada perubahan pada bobot map atau iterasi telah mencapai iterasi maksimal. 


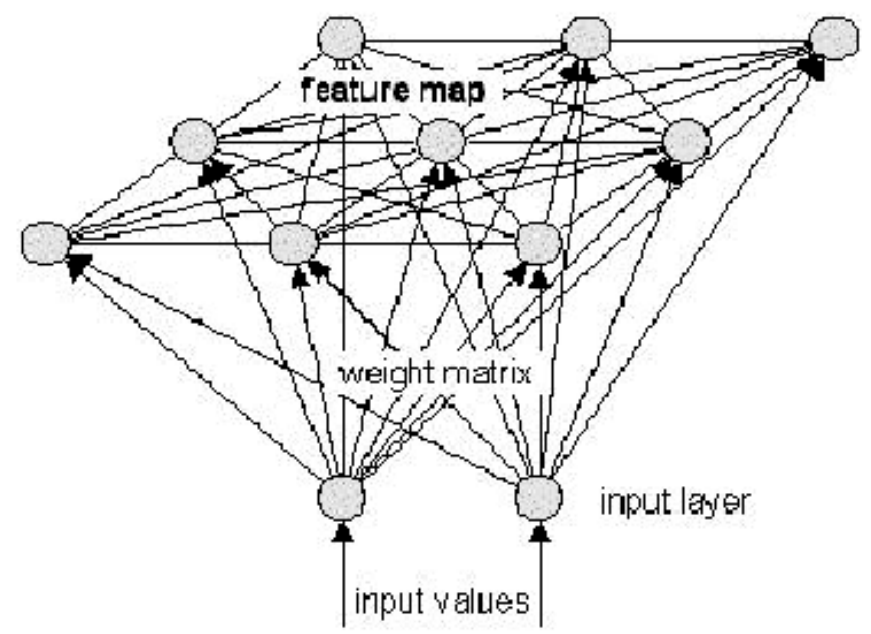

Gambar 1. Arsitektur SOM

5. Pemilihan salah satu input dari vektor input yang ada.

6. Penghitungan jarak antar vektor input terhadap bobot $\left(d_{j l}\right)$ dengan masing-masing neuron output dengan rumus pada persamaan 1 .

7. $d_{j l}=\sum_{i=1}^{n}\left(\mu_{i j l}-x_{i}\right)^{2}$

8. Dari seluruh bobot $\left(d_{j l}\right)$ dicari yang paling kecil. Index dari bobot $\left(d_{j l}\right)$ yang paling mirip disebut winning neuron.

9. Untuk setiap bobot $\mu_{i j 1}$ diperbaharui bobot koneksinya dengan menggunakan rumus yang dapat dilihat pada persamaan (3).

10. Simpan bobot yang telah konvergen.

\section{HASIL DAN PEMBAHASAN}

Pengelompokkan siswa pada penelitian ini berdasarkan pada dasar pengelompokkan kelas achievement grouping dan intelegence grouping, dimana jenis pengelompokkannya adalah Interest Grouping.

Pengelompokkan beradasarkan prestasi siswa dan hasi tes kecerdasan dapat memetakan keadaan seorang siswa untuk masuk kedalam kelompok tertentu. Selain itu faktor jenis kelamin juga menjadi variabel tambahan pada proses klasifikasi menggunakan algoritma SOM, dan nilai sikap menjadi penujang agar tidak berkumpulnya siswa-siswa dengan sikap yang kurang baik dalam satu kelas yang sama.

Nilai-nilai kecerdasan dan prestasi siswa yang diklasifikasikan menjadi 3 cluster yaitu kategori pintar, sedang, cukup. Nilai-nilai tersebut diambil dari nilai raport yang terdiri dari 3 jenis nilai, yaitu; nilai wajib-1, nilai wajib-2, dan nilai wajib-3. Setiap nilai terdiri dari 2 nilai dari masing-masing semester.

Nilai sikap dalam penelitian ini berdasarkan penilaian guru atau wali kelas yang secara keseharian berada bersama siswasiswa.
A. Langkah-langkah penerapan algoritma SOM pada pengelompokkan kelas

1. Input data yang akan menjadi data training pada algoritma SOM. Penelitian ini menggunakan 48 data nilai siswa yan dijadikan data training. Tabel 1 menunjukan data yang akan menjadi data-training

TABEL I

DAFTAR DATA TRAINING

\begin{tabular}{|c|c|c|c|c|c|c|}
\hline \multicolumn{2}{|c|}{ Wajib-1 } & \multicolumn{2}{|c|}{ Wajib-2 } & \multicolumn{2}{|c|}{ Wajib-3 } & \\
\hline 76.7170 & & & 2.00 & 6625 & 313 & \\
\hline 52 & 000 & 000 & & & 000 & \\
\hline & 167 & 708 & 67 & 50 & 063 & \\
\hline 69 & 00 & 375 & 042 & 125 & 438 & \\
\hline 70 & 00 & 77. & 76. & 625 & 13 & \\
\hline 135 & 8.4833 & 79.5917 & 78.3333 & 78.0375 & 563 & \\
\hline 900 & 78.2833 & 8.8708 & 79.3125 & 84.2375 & 83.3688 & 0.0000 \\
\hline 3.5254 & 76.1500 & 80.1583 & 78.9792 & 81.5875 & 375 & 95.0000 \\
\hline 5.6082 & 77.9833 & 78.2083 & 77.7708 & 83.5125 & 84.8000 & 70.0000 \\
\hline 77.0518 & 6.8500 & 77.8083 & 77.7500 & 76.2000 & 77.4750 & 75.0000 \\
\hline 76.1457 & 77.3000 & 72.6792 & 78.4375 & 74.0125 & 74.6125 & 000 \\
\hline 82.5020 & 81.0167 & 77.8917 & 81.0833 & 82.6625 & 82.6000 & 000 \\
\hline 74.3831 & 74.5833 & 74.6292 & 76.1042 & 77.8750 & 75.4250 & 000 \\
\hline 74.4338 & 75.6000 & 70.6917 & 76.7083 & 77.4625 & & 000 \\
\hline 75.4 & 74.8 & 74.8250 & 79.2500 & & & \\
\hline 7.0964 & 76.8 & 75.7458 & 75. & 76.2500 & 76. & 80.0000 \\
\hline & 78. & 333 & & 60 & 750 & 90.000 \\
\hline 81 & 81. & 78.0333 & 77. & 15 & & 95 \\
\hline 74 & 00 & 42 & 17 & 0 & & 00 \\
\hline 16 & 79.7667 & 74. & 80. & 76 & 25 & 75 \\
\hline 05 & 79. & 33 & 77. & 00 & 79 & 80 \\
\hline 15 & 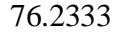 & 71. & 80. & 50 & & \\
\hline 77 & 57 & 92 & 78 & & & \\
\hline & & 72. & & & & \\
\hline & 78. & 75. & 80 & & & \\
\hline 78 & & 42 & & & & \\
\hline 92 & & 00 & 78 & 79 & & \\
\hline & & 00 & & & & \\
\hline & & & & & & \\
\hline & & 00 & & 500 & & \\
\hline & 3 & & & 77 & & \\
\hline & 10 & 72. & 76.2708 & 82 & & \\
\hline 77.1967 & 76.9 & 74.9875 & 77.1667 & 82.6750 & & \\
\hline 82.2792 & 79.8333 & 79.2042 & 81.5625 & 84.5125 & 25 & 70.0000 \\
\hline 74.0320 & 74.2833 & 76.8208 & 74.7500 & 71.0625 & 25 & 75.0000 \\
\hline 77.4844 & 76.9833 & 75.2375 & 77.5000 & 80.2000 & 82. & 80.0000 \\
\hline 80.5507 & 79.4333 & 75.6458 & 79.5625 & 79.5000 & 81. & 90.0000 \\
\hline 78.4047 & 81.6167 & 75.5292 & 79.2083 & 81.9500 & 83. & 95.0000 \\
\hline 5237 & 78 & 69.8208 & 76.9375 & 79.3875 & 63 & 70.0000 \\
\hline 070 & & 83 & 79.4 & 77.0500 & 63 & 75.0000 \\
\hline & & & 78.8 & 75.2625 & & \\
\hline & 71. & 70.2542 & 72.3 & 57.4000 & & 90.0000 \\
\hline & & & 75. & 72.7 & & \\
\hline & & & & & & \\
\hline 384 & 74. & & 76.0625 & 77.2000 & & \\
\hline 12 & 77.6167 & 70.2792 & 78.3542 & 79.2000 & & \\
\hline 868 & 77.8667 & 71.4542 & 77.8125 & 79.9875 & 79.5 & 50.0000 \\
\hline 76.6442 & 6.6500 & 71.6583 & 78.6250 & 79.8750 & 81.0313 & 40.0000 \\
\hline
\end{tabular}

2. Normalisasi data ; Metode normalisasi ini menghasilkan transformasi linier pada data asal. Bila $\min A$ dan $\max A$ adalah nilai minimun dan maksimum dari sebuah atribut A, Min-max Normalization memetakan sebuah nilai v dari A menjadi v' dalam range nilai minimal dan maksimal yang baru, new_minA dan new_maxA [2]. 
Hasil dari normalisasi data input dapat dilihat pada tabel II

TABEL II

HASIL NORMALISASI MIN MAX

\begin{tabular}{|l|l|l|l|l|l|l|l|}
\hline & \multicolumn{2}{|c|}{ Wajib-1 } & \multicolumn{2}{c|}{ Wajib-2 } & \multicolumn{2}{c|}{ Wajib-3 } & Sikap \\
\hline Maks & 82.75 & 82.15 & 83.20 & 81.56 & 85.33 & 86.28 & 95.00 \\
\hline Min & 71.34 & 71.08 & 67.74 & 72.39 & 57.40 & 57.11 & 40.00 \\
\hline
\end{tabular}

3. Membangun Jaringan; Jaringan yang dibangun berdasarkan dari hasil normalisasi pada tabel II. Dan dengan nilai:

- $\quad \operatorname{KLR}($ Kohonen Learning Rate) $=0,01$;

- $\quad$ CLR (Conscience Learning Rate) =0,001;

Jaringan yang dihasilkan pada tahapan ini memiliki bobot awal input dan nilai bias. Untuk nilai bobot awal input didapat hasil yang digambarkan pada gambar 2:

Bobot awal input $=$

$\begin{array}{lllllll}77.0530 & 76.6167 & 75.4750 & 76.9792 & 71.3687 & 71.7000 & 67.5000\end{array}$ $\begin{array}{lllllll}77.0530 & 76.6167 & 75.4750 & 76.9792 & 71.3687 & 71.7000 & 67.5000\end{array}$

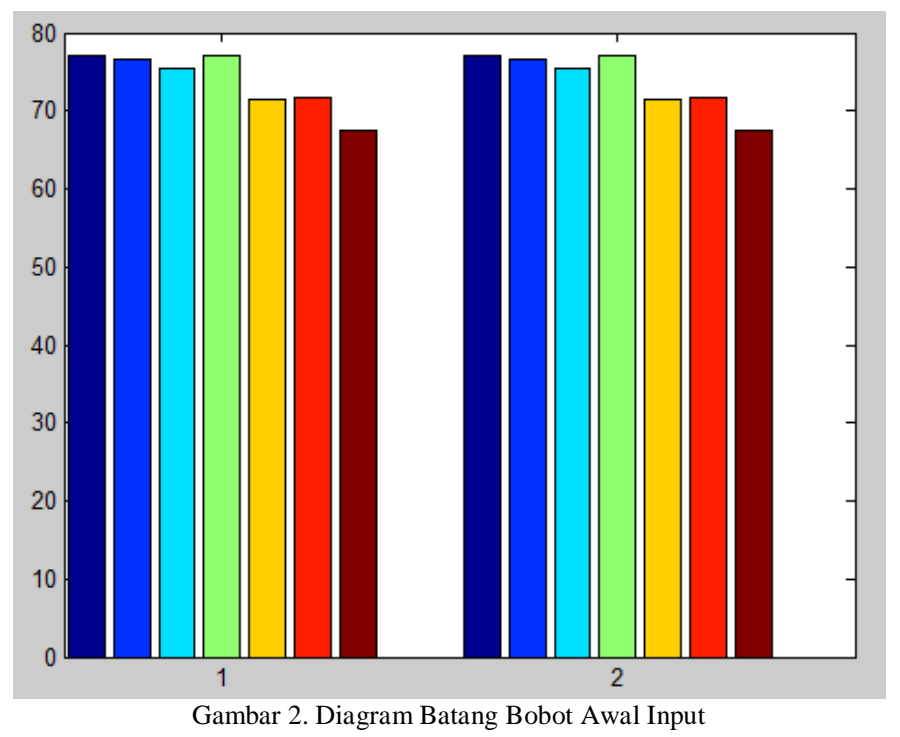

Nilai Bias $=$

5.4366

5.4366

4. Pelatihan Jaringan, pelatihan jaringan dilakukan dengan parameter sebagai berikut:

- Jumlah epoch $=1000$

- Jumlah goal per epoch $=0,0001$

Hasil dari pelatihan jaringan tersebut menghasilkan nilai bias dan nilai bobot yang baru.

Nilai Bobot:

$\begin{array}{lllllll}77.2732 & 77.2488 & 74.7259 & 77.8520 & 78.1811 & 78.6156 & 88.0230\end{array}$

$\begin{array}{lllllll}77.1587 & 77.1459 & 73.6517 & 77.7995 & 77.8713 & 79.5687 & 68.3832\end{array}$

Nilai Bias:

5.2750

5.6083

\section{Melihat hasil clustering}

Seperti diuraikan di muka bahwa untuk penentuan klasifikasi siswa didasarkan pada mean persentase keselurahan nilai dari seluruh anggota cluster. Mean tinggi menunjukkan tingkat kecerdasan siswa tersebut baik. Sebaliknya mean rendah menunjukkan tingkat kecerdasan siswa tersebut kurang baik. Sedangkan mean di antara tinggi dan rendah berarti siswa tersebut masuk dalam kategori sedang.

Hasil dari data training dapat dilihat pada gambar 3.

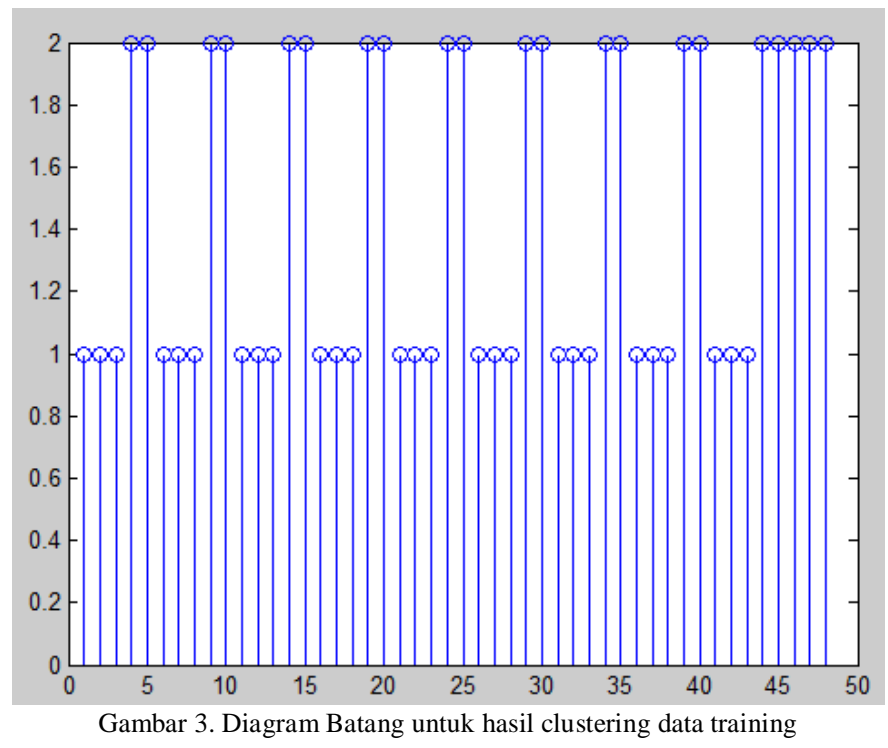

\section{B. Tampilan Aplikasi}

Hasil pada pelatihan algoritma SOM dijadikan sebagai dasar untuk melakukan pengecekan terhadap data-data lainnya termasuk kedalam cluster yang mana.

Untuk mempermudah penggunaan, maka diperlukan sebuah aplikasi yang user friendly. Secara umum kegunaan dari interface adalah untuk berkomunikasi dengan user. Pada aplikasi ini digunakan 2 macam interface yaitu:

1. Interface halaman utama seperti terilhat pada gambar 4 merupakan tampilan aplikasi utama dari program pengelompokkan kelas.

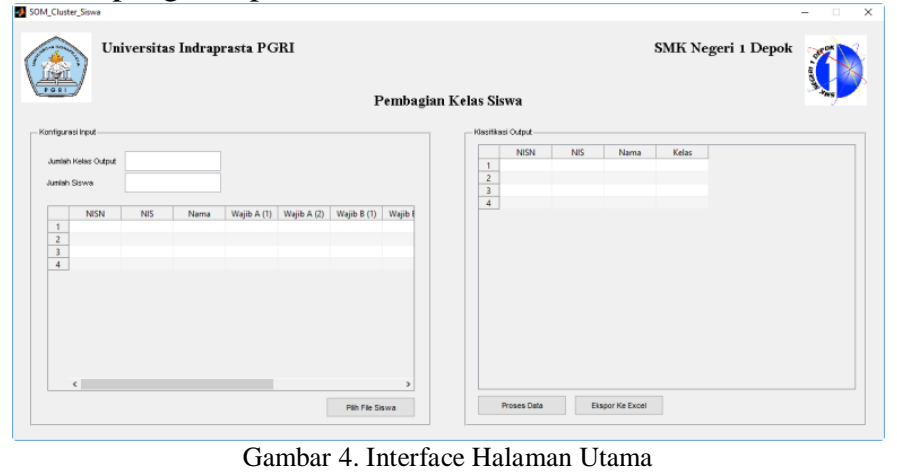

2. Interface halaman pemilihan file data siswa; digunakan untuk memilih file data siswa berformat .xls 


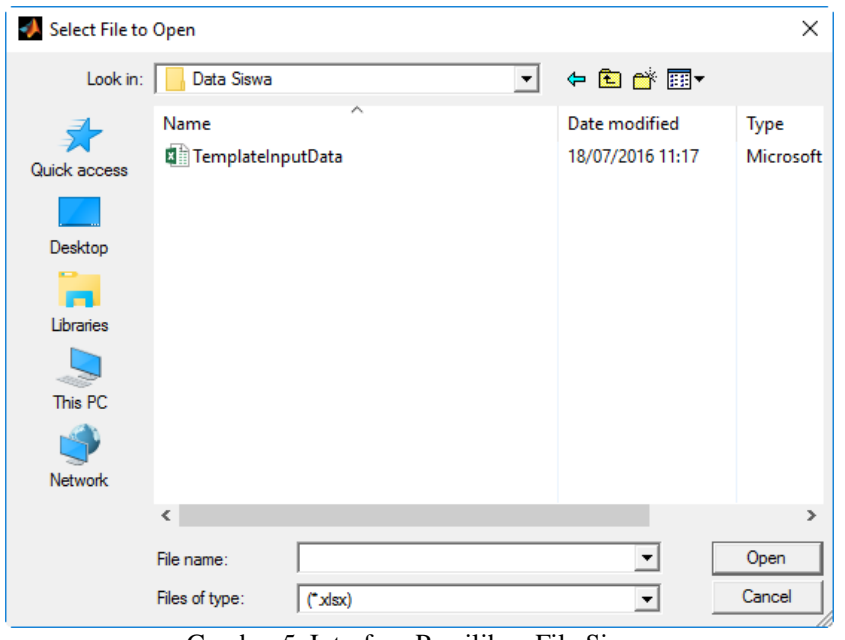

Gambar 5. Interface Pemilihan File Siswa

\section{Penggunaan Aplikasi}

Proses Penggunaan Aplikasi Pengelompokkan Kelas Menggunakan Self Organizing Map Neural Network.

1) Jalankan aplikasi sehingga muncul tampilan utama (gambar 4).

2) Isikan banyaknya kelas yang akan menjadi target pengelompokkan pada isian jumlah kelas output.

3) Isikan banyaknya siswa yang akan dikelompokkan pada isian Jumlah Siswa.

4) Klik tombol pilih file siswa sehingga tampil jendela pilih file untuk memasukan siswa kedalam aplikasi (gambar 5).

5) Pilih file excel yang telah menjadi template data siswa, kemudian klik tombol open. Sehingga data akan tampil pada tabel data siswa, lihat gambar 6 .

\begin{tabular}{|c|c|c|c|c|c|}
\hline & NISN & Nama & Wajib 1 - (1) & Wajib 1 - (2) & Wajib \\
\hline 1 & 9997575731 & Abad Salim Hidayatullah & 76.7170 & 75.4667 & $7 n$ \\
\hline 2 & 9995050294 & Abdul Rosid & 75.8252 & 74.7000 & 7 \\
\hline 3 & 9994811275 & Adhiyaksa & 79.7390 & 77.8167 & 7 \\
\hline 4 & 9986773372 & Ahmad Zulnika Putra & 74.1369 & 73.6000 & 7 \\
\hline 5 & 9998896104 & Ahmed Rayhan Primadedas & 76.5471 & 77.1000 & 7 \\
\hline 6 & 9995050335 & Alif Ramadhan Anda & 76.7435 & 78.4833 & 7 \\
\hline 7 & 9981294117 & Andre Berliansyah & 82.1900 & 78.2833 & 7 \\
\hline 8 & 9990968049 & Annisa Rinjani Putri & 78.5254 & 76.1500 & 8 \\
\hline 9 & 9994811298 & Ardhika Fajar Ramadhan & 76.6082 & 77.9833 & 7 \\
\hline 10 & 9995131179 & Atnan Shaleh & 77.0518 & 76.8500 & 7 \\
\hline 11 & 9997034193 & Bagus Sulaeman & 76.1457 & 77.3000 & 7 \\
\hline 12 & 9993606119 & Dhymas Alamsyah & 82.5020 & 81.0167 & 7 \\
\hline 13 & 9995133389 & Fani Amalia & 74.3831 & 74.5833 & $7 \mathrm{v}$ \\
\hline & $<$ & & & & $>$ \\
\hline
\end{tabular}

Gambar 6. Tampilan Tabel Daftar Siswa

6) Kemudian klik tombol proses data untuk melakukan proses klasifikasi, tunggu hingga proses selesai. Hasil dari proses klasifikasi akan ditampilkan pada tabel klasifikasi output. Lihat gambar 7:

\begin{tabular}{|c|c|c|c|c|}
\hline & NISN & Nama & Kel & \\
\hline 1 & 0009394290 & Siti Anisah & A & $\wedge$ \\
\hline 2 & 9995130930 & Noor Putri Indahsari & A & \\
\hline 3 & 9995975723 & Muhammad Fikri Guntur Ardiansyah & A & \\
\hline 4 & 9995130940 & Farhan Putra Pratama & A & \\
\hline 5 & 9983456490 & Thommi Fauzi & A & \\
\hline 6 & 9997034193 & Bagus Sulaeman & A & \\
\hline 7 & 000000 & Helen Imelda Sitorus & A & \\
\hline 8 & 9995133686 & Mela Hidayah & A & \\
\hline 9 & 9993515518 & Saefullah Fatah & A & \\
\hline 10 & 9997034738 & Fuad Munandar & A & \\
\hline 11 & 9995131179 & Atnan Shaleh & A & \\
\hline 12 & 9995098615 & Wunia Moyongo Permata & A & \\
\hline 13 & 9995039364 & Yuliana Resty Fauzy & A & \\
\hline 14 & 9992402848 & Mikail Habibullah & A & \\
\hline 15 & 9994811169 & Krisna Fathurrachman & A & \\
\hline 16 & 9995050335 & Alif Ramadhan Anda & A & \\
\hline 17 & 9983394407 & Novita Dwi Wahyuni & A & \\
\hline 18 & 999675188 & Muhammad Tio Febiansyah & A & 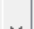 \\
\hline
\end{tabular}

Hasil proses klasifikasi dapat di ekspor kedalam format file excel dengan cara memilih tombol ekspor ke excel. File hasil ekspor akan berada dalam satu folder dengan lokasi dimana aplikasi tersebut berada, dengan nama file data $<$ tahunBulanTanggalWaktu>.xlsx

contoh : data20160716205252.xlsx

\section{Pengujian}

Pengujian pada penelitian ini dilakukan terhadap hasil algoritma dan terhadap aplikasi. Pengujian dilakukan secara black box:

1) Pengujian data training

Tabel III menunjukan hasil pengujian terhadap data training:

TABEL III

Hasil PENGUJian DATA TRAINING

\begin{tabular}{|l|l|l|}
\hline No & \multicolumn{1}{|c|}{ Elemen Pengujian } & Hasil \\
\hline 1 & $\begin{array}{l}\text { Anggota kelompok setiap cluster } \\
\text { berisi jumlah yang sama }\end{array}$ & OK \\
\hline 2 & $\begin{array}{l}\text { Setiap cluster memiliki jumlah siswa } \\
\text { yang merata dari sisi jenis kelamin }\end{array}$ & OK \\
\hline
\end{tabular}

2) Pengujian aplikasi

Tabel IV menunjukan hasil pengujian terhadap aplikasi

TABEL IV

HASIL PENGUJian APLIKASI

\begin{tabular}{|c|l|c|}
\hline No & \multicolumn{1}{|c|}{ Elemen Pengujian } & Hasil \\
\hline 1 & $\begin{array}{l}\text { Dapat menginput data siswa } \\
\text { berformat xls tanpa memunculkan } \\
\text { pesan error }\end{array}$ & OK \\
\hline 2 & $\begin{array}{l}\text { Dapat menghasilkan jumlah } \\
\text { kelas/cluster sesuai dengan inputan } \\
\text { parameter }\end{array}$ & OK \\
\hline 3 & $\begin{array}{l}\text { Dapat menghasilkan file excel } \\
\text { (export) hasil daripada pengolahan. }\end{array}$ & OK \\
\hline 4 & $\begin{array}{l}\text { Anggota kelompok setiap cluster } \\
\text { berisi jumlah yang sama }\end{array}$ & OK \\
\hline 5 & $\begin{array}{l}\text { Setiap cluster memiliki jumlah siswa } \\
\text { yang merata dari sisi jenis kelamin }\end{array}$ & OK \\
\hline
\end{tabular}




\section{KESIMPULAN}

Algoritma Self-Organizing Map (SOM) dapat melakukan pengklasifikasian siswa secara merata pada setiap kelas yang ditentukan. Setiap kelas memiliki jumlah siswa yang sama, perbandingan siswa pria dan wanita yang merata dan juga tentunya pengelompokkan siswa-siswa dengan kemampuan yang merata disetiap kelas. Hal ini dapat menjadikan suasana kelas yang nyaman. Hasil dari penerimaan guru sebagai pengguna merasa hasil yang didapat sangat baik dan sesuai dengan penilaian nalar merekas sebagai manusia.

\section{REFERENSI}

[1] Peraturan Menteri Pendidikan dan Kebudayaan (Permendikbud) Nomor 32 Tahun 2013

[2] Soetopo, H. 1982. Pengantar Operasional Administrasi pendidikan. Malang: IKIP Malang

[3] Ranchman, Maman. 1999. Manajemen Kelas. Semarang: Depdikbud

[4] Imron, A. 2012. Manajemen Peserta Didik Berbasis Sekolah. Jakarta:PT Bumi Aksara

[5] Tim dosen AP. 2001. Manajemen pendidikan. Yogyakarta : UNY Pres

[6] Dessy Setiani dan RB.Fajriya Hakim, Clustering Indikator Pembangunan Berkelanjutan Di Indonesia Menggunakan Algoritma Self-Organizing Maps (Soms) Kohonen. Prosiding Seminar Nasional Matematika dan Pendidikan Matematika UMS. 2015. Hal. 614-628, ISBN: 978.602.361.002.0

[7] G. S. Budhi, Liliana, S. Harryanto, Cluster Analysis Untuk Memprediksi Talenta Pemain Basket Menggunakan Jaringan Saraf Tiruan Self Organizing Maps (SOM), Jurnal Informatika Vol. 9, No. 1, MEI 2008: $23-32$.

[8] Kartika P, Candra D, Imam. Identification Of Patchouli Leaves Quality Using Self Organizing Maps (SOM) Artificial Neural Network, Journal of Environmental Engineering \& Sustainable Technology, Vol. 03 No. 01, July 2016, Hal 42-50

[9] Yunus Anis, R.Rizal Isnanto. Penerapan Metode Self-Organizing Map (SOM) Untuk Visualisasi Data Geospasial Pada Informasi Sebaran Data Pemilih Tetap (DPT), Jurnal Sistem Informasi Bisnis, Vol 01, Hal 4857.

[10] Mishra, Madhusmita dan H.S Behera, Kohonen Self Organizing Map with Modified K-means clustering For High Dimensional Data Set International Journal of Applied Information System (UAIS)ISSN :2249-0808. Foundation of Computer Science FCS, New York, USA. Vol.2, No.3. 2012

[11] Suyanto. 2007. Artificial Intelligence; Searching, Reasoning, Planning, and Learning. Bandung: Penerbit Informatika.

[12] Fausett, L. 1994. Fundamentals of Neural Network; Architecture, Algorithms and Applications. Prentice Hall.

[13] Juha Vesanto dan Esa Alhoniemi, Clustering of the Self-Organizing Map, IEEE TRANSACTIONS ON NEURAL NETWORKS, VOL. 11, NO. 3, Mei 2000.

[14] Han, Jiawei, dan Micheline Kamber, Data Mining: Concepts and Techniques, Morgan Kaufmann, 2001.

[15] Kainulainen, Jukka, Clustering Algorithms: Basics and Visualization, Finland: Helsinky University of Technology, 2002.

[16] Setiawan, Kuswara, Paradigma Sistem Cerdas, Artificial Intellegence, Bayumedia Publishing, 2003.

[17] Kohonen, Teuvo, The Self Organizing Map, IEEE, Sept. 1990. Stiroh, Kevin J. Playing for Keep: Pay and Performance in NBA, June 2003, http://www. nba.com, February 2006 